\title{
Yeni Para Politikası Yaklaşımı Çerçevesinde Kullanılan Rezerv Opsiyon Mekanizması Etkinliğinin Analizi*
}

\author{
S. Nurbanu YILDIZ ${ }^{* *}$ Başak KARŞIYAKALI ${ }^{* * *}$ Üzeyir AYDIN ${ }^{* * * * *}$
}

\begin{abstract}
$\ddot{O} Z$
Küresel kriz sonrası yaşanan süreç pek çok gelişmekte olan ülke merkez bankaları gibi Türkiye Cumhuriyet Merkez Bankası'nı da yeni para politikası araçları tasarlamaya zorlamıştır. Bu tasarım perspektifinde zorunlu karşılık oranları, rezerv opsiyonu mekanizması (ROM) ve asimetrik faiz koridoru uygulamaya konulmuştur. Uygulamayla birlikte söz konusu araçların etkinliği ve başarısı tartışılmaya başlanmıştır. Bu kapsamda çalışmanın amacı Türkiye'de 2010'dan beri uygulanmakta olan ROM'un döviz rezerv değişimi, döviz kuru, enflasyon belirsizliği, enflasyon oranı ve faiz oranları üzerindeki etkisini araştırmak ve mekanizmanın etkinliğini analiz etmektir. Çalışmada 2011 Ekim - 2018 Aralık dönemi veri setini içeren analizler için Otoregresif Koşullu Değişen Varyans (GARCH) modellerinden yararlanılmıştır. Elde edilen sonuçlara göre ROM'un finansal kırılganlığı, döviz kurunu, enflasyon belirsizliğini, enflasyon ve faiz oranlarını etkileme gücü zaylf bulunmuştur.
\end{abstract}

Anahtar Kelimeler: Rezerv Opsiyonu Mekanizması, Finansal Istikrar, GARCH Modelleri, Yeni Para Politikası Araçları, Rezerv Opsiyon Katsayısı

JEL Sinıflandırması: D53, D81, G18, E47

\section{Analysis of the Effectiveness of the Reserve Option Mechanism Used in the Framework of the New Monetary Policy Approach}

\begin{abstract}
The post-global crisis has urged the "Central Bank of the Republic of Turkey (CBRT)" to design new monetary policy instruments, as have the central banks of many developing countries. In this prospect; reserve requirement ratio, reserve option mechanism (ROM) and asymmetric interest rate corridor instruments were put into practice. With the application, the effectiveness and success of the instruments in the subject began to be examined. In this context; the study aims to analyse the effect of the ROM in Turkey, on foreign exchange reserves, exchange rate, inflation uncertainty, inflation rate and interest rates and to review the effectiveness of the mechanism. In the study, "Generalized Autoregressive Conditional Heteroskedasticity (GARCH)" models were employed for analyses, covering the October 2011 - December 2018 period. Consequently, ROM's strength to influence financial fragility, exchange rate, inflation uncertainty, inflation and interest rates, was found to be limited.
\end{abstract}

Key Words: Reserve Option Mechanism, Financial Stability, GARCH Models, New Monetary Policy Instruments, Reserve Option Coefficient

JEL Classification: D53, D81, G18, E47

\footnotetext{
* Bu çalışma Sevim Nurbanu YILDIZ'ın yüksek lisans tezinden türetilmiştir.

${ }^{* * *}$ Dokuz Eylül Üniversitesi Sosyal Bilimler Enstitüsü İktisat Bölümü Yüksek Lisans öğrencisi, nurbanu.koyukan@gmail.com, ORCİD Bilgisi: 0000-0002-2316-9154

****Dr.Öğr.Üyesi, Dokuz Eylül Üniversitesi İktisadi ve İdari Bilimler Fakültesi İktisat Bölümü, basak.kacmaz@deu.edu.tr, ORCID Bilgisi: 0000-0002-3835-0175

${ }^{* * * * * *}$ Doç. Dr., Dokuz Eylül Üniversitesi İktisadi ve İdari Bilimler Fakültesi İktisat Bölümü, uzeyir.aydin@deu.edu.tr, ORCID Bilgisi: 0000-0003-2777-6450
}

(Makale Gönderim Tarihi: 09.07.2019 / Yayına Kabul Tarihi:07.12.2020)

Doi Number: 10.18657/yonveek.599119

Makale Türü: Araştırma Makalesi 


\section{GİRIŞ}

Merkez Bankası'nın birçok amaç ve hedefinin yanı sıra temel hedefi fiyat istikrarını sağlamaktır. Bunun için parasal hedefleme ve döviz kuru hedefleme stratejileri kullanabileceği gibi Türkiye'de başvurulduğu üzere enflasyon hedeflemesi de uygulanabilmektedir. Ancak küresel hale gelen 2008 finansal krizi sonrasında ekonomideki parasal genişlemenin kontrol altına alınabilmesi için yeni politika bileşimleri oluşturulmuştur. $\mathrm{Bu}$ anlamda Merkez Bankası'nın fiyat istikrarı amacının yanı sıra finansal istikrarın da sağlanması gerekliliği sorgulanmış ve bu yönde politikalar geliştirilmiştir. Çünkü para arzının kontrolü ile fiyat istikrarı sağlanmaya çalışılırken, diğer yandan makroekonomik değişkenlerde oluşan oynaklıklar ekonomide istikrarsızlığa yol açmıştır. 2010 yılının ortalarından itibaren küresel krizin ekonomiye olan yansımalarını ortadan kaldırmak, finansal yapıyı güçlendirmek ve ekonomide tam anlamıyla istikrarın oluşması sağlamak için yeni politika araçları kullanılmaya başlanmıştır. Merkez Bankası bu doğrultuda faiz koridoru, zorunlu karşıllklar, likidite yönetimi politika araçlarının yanında sermaye hareketlerindeki aşırı oynaklığın makroekonomik ve finansal istikrar üzerindeki olumsuz etkilerinin sinırlandırılması ve "yastık altı" birikimlerin ekonomiye kazandırılması için otomatik dengeleyici rolünde rezerv opsiyon mekanizmasını (ROM) geliştirmiştir.

Bankaların TL cinsinden zorunlu karşılık tutma yükümlülüklerini gerçekleştirirken bu zorunlu karşılıkların Merkez Bankası tarafından belirlenen oran kadarını döviz (Amerikan doları veya EURO) veya altın cinsinden tutma imkanı sağlayan mekanizma ROM olarak adlandırılmaktadır. Merkez Bankası'nın zorunlu karşılıkların ne kadarının altın veya döviz cinsinden tutulacağını gösteren katsayıya ise rezerv opsiyonu katsayısı (ROK) denilmektedir.

Merkez Bankası geliştirmiş olduğu yeni politika aracı olan ROM ile döviz likiditesi, kur oynaklıkları, sermaye hareketlerinin kontrol ve yönetimi sağlanmaktadır. ROM'un ne kadar kullanılacağı Merkez Bankası'nın belirlediği ve rezerv oranı katsayısı olarak ifade edilen yüzdelik dilimlere ilişkin katsayılar ile çarpılarak bulunmaktadır. Bankalar TCMB'de tutmakla zorunlu oldukları yükümlülükler için kaynak maliyetini esas almaktadır. Buna göre; bankalar sermaye girişlerinin yoğun olduğu dönemlerde TL yükümlülükleri için ayıracakları zorunlu karşılıkların büyük kısmını döviz kaynak maliyeti düşük olması nedeniyle döviz cinsinden tutmak istemektedirler. Tam tersi durumda bankalar sermaye çıkışlarının olduğu dönemlerde ise döviz kaynak maliyeti artacağından zorunlu karşılıkları TL cinsinden tutmak istemektedirler.

Dolayısıyla para politikası araçlarının gelişimi ve eski-yeni politika araçlarının bir arada kullanılmasıyla birlikte parasal kontrol ve likidite yönetiminde zorunlu karşılıkların rolü artmıştır. Enflasyon hedeflemesi rejiminde zorunlu karşı1ıklar, aktarım mekanizması çerçevesinde bankaların fon bulması ve buna bağlı olarak firmaların kredi taleplerinin karşılanması yoluyla kredi kanalı üzerinde etkili olmaktadır. Bu şekilde TCMB zorunlu karşılıklar ile kredi arzını yönetmektir. Faiz koridorunda ise faizlerin artması veya azalması ile TCMB bankaların fon maliyetini ve kredi arzlarını etkilemektedir. TCMB, kredi kanalı 
üzerinden zorunlu karş1lıklar ile faiz koridorundaki alt ve üst bantların belirlenmesiyle, bankaların fon bulma maliyeti ve firmalara sağladığ 1 kredi hacimleri üzerinden ekonomide likidite yönetimini yapmaktadır.

Merkez Bankası faiz koridorunu etkin bir şekilde kullanabilmek için sermaye çıkışı olduğu dönemlerde, döviz kurunun artmaması için koridor bandını daraltarak faiz oranlarını yükseltir. Faiz oranlarındaki bu yükseliş bankaların Merkez Bankası'ndan kredi bulma maliyetlerini arttırır. Bankalar fon maliyetlerini düşürmek için ellerindeki yabancı paraları satarak piyasaya döviz likiditesi bırakır ve böylece kurda meydana gelen artış baskılanmış olur.

Merkez Bankası, bankaların TL cinsinden zorunlu karşılık tutma yükümlülüklerini gerçekleştirirken zorunlu karşılıkların, belirlenen oran kadarını döviz veya altın cinsinden tutma imkânı sağlayan ROM ile döviz likiditesi, kur oynaklıkları, sermaye hareketlerinin kontrolünü ve yönetimini sağlamaya çalışmaktadır. Bankalar TCMB'de tutmakla zorunlu oldukları yükümlülükler için kaynak maliyetini esas almaktadır. Bankalar sermaye girişlerinin yoğun olduğu dönemlerde TL yükümlülükleri için ayıracakları zorunlu karşılıkların büyük kısmını döviz kaynak maliyeti düşük olması nedeniyle döviz cinsinden tutmaktadırlar. Bankalar sermaye çıkışının olduğu dönemlerde ise döviz kaynak maliyeti artacağından zorunlu karşılıkları TL cinsinden tutmaktadırlar. Bu şekilde TCMB'nin brüt döviz rezervleri etkilenmektedir. Ülkeye sermaye akımının yoğun olduğu dönemlerde kur düşmekte, TL değer kazanmakta ve ekonomide TL cinsinden varlıkların fiyatları artmaktadır. Bu durumda bankaların TL faizleri düşmekte ve kredi teminatları güçlenmektedir. Düşük faiz oranı ile kredi talep eden firmalara bankaların sunduğu kredi kolaylığı ile kredi hacmi artmaktadır. Artan kredi, ithalatı artırarak cari açığa neden olmaktadır.

TCMB, faiz koridorunu, zorunlu karşıllkları ve ROM oranlarını değiştirerek bahsedilen bu süreci ve bankaların fon bulma maliyetlerini etkilemek suretiyle piyasadaki likiditeyi ve aktarım kanallarını yönetmeye çalışmaktadır. Bu kapsamda para, döviz ve finans piyasalarında otomatik dengeleyici olarak tasarlanan ROM'un kendisinden beklenen başarıy1 gösterip göstermediği çalışmada temel sorunsal olarak ele alınmaktadır. Bu sorunsaldan hareketle çalışmada amaç, ROM'un döviz rezerv değişimi, döviz kuru, enflasyon belirsizliği, enflasyon ve faiz oranları üzerindeki etkisini incelemektir. ROM kullanım oranında meydana gelen negatif ve pozitif şokların analize dahil edilen değişkenler üzerindeki etkisinin bütüncül bir yaklaşımla ölçülmesi, daha uzun hafizayla ve daha esnek gecikme yapısıyla bu parametrelerdeki değişkenliğin kaynağının saptanması bu çalışmanın literatüre önemli bir katkısı olacaktır. Bu çerçevede ilerleyen bölümlerde ilk olarak literatür taramasına yer verilmiştir. Ardından analizlerde kullanılan yöntem ve veri seti ele alınmıştır. Son olarak ampirik bulgular analiz edilmiş ve analizlerden türetilen politik önermelere yer verilerek çalışma tamamlanmıştır.

\section{LITERATÜR ÖZETI}

Literatürde konuya ilişkin çok sayıda çalışma yapılmış olmakla birlikte burada kısaca Türkçe literatüre değinilmiştir. Alper vd. (2012)'de işleyişini 
örneklerle açıkladıkları ROM'un makroekonomik ve finansal istikrar amaçları doğrultusunda faydalı bir araç olduğunu tespit etmişlerdir. Çalışmada sermaye girişlerinin döviz kuru ve yabancı para cinsi krediler üzerindeki negatif etkilerinin sınırlanması bakımından ROM'un benzer diğer araçlara göre daha etkili olduğu da vurgulanmıştır. Ayrıca ROM'un zaman içinde çeşitli şoklara karşı sınanması gerektiği de çalışmada ifade edilmiştir.

Küçüksaraç ve Özel (2012)'de Türk lirası zorunlu karşılık tesis etmek amacıyla kullanılabilecek temel fon kaynaklarının maliyetlerini ve TCMB'nin Türk lirası zorunlu karşılıklar için döviz ve altın bulundurma imkânını diğer fonlama maliyetleriyle kayıtsız bırakan ROK değerlerini incelemişlerdir. Yazarlar TCMB'nin ROM'u ve ROK'u optimal bir şekilde uygulaması durumunda brüt döviz rezervlerini arttırarak bankaların kredi büyümesini kontrol edilebileceğini tespit etmişlerdir. Ayrıca ROK'u değiştirilmesiyle kısa vadeli faiz oranlarının da etkilenebileceği çalışmada vurgulanmıştır.

Demirhan (2013), Türkiye'de merkez bankası yeni politika yaklaşımının finansal istikrar üzerindeki etkisini TCMB örneği aracılı̆̆ıyla incelemiştir. Çalışmada yeni politika yaklaşımı çerçevesinde zorunlu karşılık oranları, ROM ve asimetrik faiz koridoru ele alınarak, TCMB'nin bu araçları etkin bir biçimde kullandığı sonucuna ulaşılmıştır.

Oduncu vd. (2013), 15.10.2010 ve 15.10.2012 verilerini dikkate alarak ROM'un kur oynaklığı üzerindeki etkisini GARCH modeli ile araştırmışlardır. Çalışmada ROM'un kur oynaklığını düşürücü yönde etkisinin olduğu tespit edilmiştir.

Serel ve Özkurt (2014), 2010 yılı sonrası uygulamaya başlanan para politikası karmasının ortaya çıkış sürecini, uygulama aşamasında yaşanan gelişmeleri ve sonuçlarını, TCMB kaynaklarını inceleyerek gözleme dayalı bir çalışma ile ortaya koymuşlardır. Yazarlar ROM uygulamasının TL. volatilitesini azalttığı sonucuna ulaşmışlardır.

Alkın (2015), ileriye dönük Taylor kuralının TCMB para politikasındaki geçerliliğini, 2006 yılı Ocak ve 2015 yılı Şubat arasındaki dönem için aylık verileri dikkate alarak araştırmıştır. Çalışmada yeni uzlaşı modeli, reel faiz oranı ile faiz düzleştirme değişkeni, enflasyon açığı, çıktı açığı ve döviz kuru arasındaki ilişki Johansen eş bütünleşme testi ve nedensellik testi kullanılarak incelenmiştir. Çalışmada gerçekleşen enflasyon oranının, beklenen enflasyon oranından yüksek olması durumunda TCMB'nin faiz oranlarını arttırdığı ve faiz kararı alırken de geçmiş dönem faiz oranlarını dikkate aldığı sonucuna ulaşmış ve finansal istikrar konusunda faiz oranlarına dikkat çekilmiştir.

Ergin ve Aydın (2017) çalışmalarında para politikasının finansal istikrarı sağlamadaki rolünden bahsederek ROM'un inşa süreci ve kapsamına değinmişlerdir. Yazarlar ayrıca ROM'un olası bir krizde finansal yapının daha güçlü ve dirençli olmasını sağladığını, döviz rezervlerini güçlendirdiği, kurlarda yaşanan oynaklığı sınırlandırdığı ve tasarrufların yatırıma dönüştürülmesinde etkin rol oynadığı tespit edilmiştir. 
Kantar (2017), 2011-2016 dönemi için GARCH yaklaşımını kullanarak ROM'un döviz kuru volatilitesine etkisini araştırmıştır. Çalışmada ROM'un döviz kuru volatilitesini azalttığı ve negatif şoklara karşı ROM'un etkili olduğu tespit edilmiştir.

Keskin (2018), TCMB tarafindan uygulamaya konulan yeni para politikası yaklaşımının benimsenmesinde ve politika araçlarının kullanımında sermaye akımlarının rolünü araştırmıştır. Yazar, Türkiye'de sermaye akımlarının tamamen serbest olduğu, ekonomik büyüme sürecinin büyük ölçüde sermaye akımları tarafından belirlendiği ve ülkeye yönelen sermaye akımlarının içsel faktörlerden ziyade küresel ekonomik koşullara bağlı olduğuna vurgu yapmıştır. Çalışmada, sermaye akımlarının yol açtığı istikrarsızlıkların yalnızca para politikası araçları ile önlenebilmesinin zor olduğu sonucuna ulaşılmıştır.

Tezer (2019), ROM'un döviz rezerv pozisyonu açısından faydalı olduğunu tespit etmiştir. Yazar ayrıca ROM'un makro ekonomik yapıdaki olumsuzluklardan dolayı kırılganlıkları, döviz kuru ve faizler üzerindeki kontrol gücünü etkilemekte yetersiz kaldığı sonucuna da ulaşmıştır.

Ele alınan literatür bir bütün olarak değerlendirildiğinde ROM'un bankalara yarar sağladığı, döviz kuru oynaklığını azalttığı, döviz rezervlerini güçlendirdiği ve finansal istikrarın sağlanmasına katkı verdiği şeklinde sonuçlar üretildiği görülmektedir. Aksi yönde bulgulara az da olsa rastlamak mümkündür.

\section{AMAÇ VE HIPPOTEZLER}

Çalışmanın amacı, TCMB'nin 2010'dan beri uygulamakta olduğu ROM'un döviz rezerv değişimi, döviz kuru, enflasyon belirsizliği, enflasyon ve faiz oranları üzerindeki etkisini analiz etmektir. Diğer bir ifadeyle ROM'un etkinliğini sınamaktır. ROM uygulamasındaki beklentiler dikkate alındığında çalışmanın amacı çerçevesinde aşağıdaki hipotezler oluşturulmuştur.

Hipotez 1: ROM, TCMB döviz rezervlerindeki volatiliteyi azaltıcı bir etkiye sahiptir.

Hipotez 2: ROM, enflasyon belirsizliği üzerinde azaltıcı bir etkiye sahiptir.

Hipotez 3: ROM, döviz kuru volatilitesi üzerinde azaltıcı bir etkiye sahiptir.

Hipotez 4: ROM, döviz rezerv pozisyonu açısından faydalıdır.

Hipotez 5: ROM, finansal kırılganlıkların azaltılmasında, döviz kurunun ve faiz oranlarının kontrol edilmesinde etkindir.

\section{YÖNTEM}

Hipotezlerin testi için araştırmada ilk olarak otoregresif hareketli ortalama süreci (ARMA) tercih edilmiş ve uygun model belirlenmiştir. Ardından otoregresif koşullu değişen varyans modellerinden (GARCH, IGARCH, EGARCH vb.) yararlanılmıştır. Çalışmanın ilerleyen bölümlerinde kısaca bu modellere değinilmiştir. 


\section{A. Otoregresif Hareketli Ortalama Süreci (ARMA Modeli) ${ }^{1}$}

Zaman serisi modeli hem AR, hem de MA bileşenleri $p$ ve q'uncu dereceden olmak üzere $\operatorname{ARMA}(\mathrm{p}, \mathrm{q})$ olarak tanımlanabilir. Birinci siradan hareketli ortalama, MA(1), spesifikasyonu aşağıdaki gibidir:

$$
Y_{t}=\mu+e_{t}+\theta e_{t-1}
$$

burada $\left\{e_{t}\right\}$ beyaz gürültülüdür ve $\mu$ ve $\theta$ sabitlerdir. "Hareketli ortalama" terimi $Y_{t}$, e'nin son son iki değerinin, ortalamaya benzer şekilde, ağırlıklandırılmış toplamdan elde edilmesinden gelmektedir. $Y_{t}$ 'nin beklenen değeri, $Y_{t}$ 'nin varyans1 ve birinci otokovaryans süreci işletilir. Birinci düzeyden otoresgresyon süreci, AR(1), aşağıdaki gibidir:

$$
Y_{t}=c+\emptyset Y_{t-1}+e_{t}
$$

Durağan $A R(1)$ sürecinin ortalamas1, $A R(1)$ sürecinin varyans1 ve $j$. inci otokovaryans1 süreci işletilir. $\mathrm{Bu}$ süreçler sonucunda Otoregresif hareketli ortalama, ARMA(p,d,q) modeli,

$$
Y_{t}=\mu+\gamma_{1} Y_{t-1}+\gamma_{2} Y_{t-2}+\cdots+\gamma_{p} Y_{t-p}+e_{t}+\theta_{1} e_{t-1}-\cdots-\theta_{q} e_{t-q}
$$

elde edilir.

ARMA (p,d,q) modelleri, Box ve Jenkins (1970) tarafından tartışılmıştır. $\mathrm{d}$ ifadesi, veriyi durağan hale getirmek için kaçıncı dereceden farkının alındığını göstermektedir. Diğer ifadeyle d sayısı karakteristik denklemdeki birim köklerin sayısına eşittir. Ayrıca, p otogresif (gecikmeli bağımlı değişken) terimi ve q gecikmeli hareketli ortalama terimini ifade etmektedir. Yapılan çalışmalar, küçük $\mathrm{p}$ ve q değerlerine sahip kısa modellerde daha etkin bir tahminlemeye neden olmaktadır (Said ve Dickey, 1984: 599, Greene, 2002: 610).

\section{B. Otoregresif Koşullu Değișen Varyans Modelleri ${ }^{2}$}

Sabit, ortalama ve varyanslı olmadıklarından dolayı çoğu ekonomik zaman serilerinin modellenmesinde bilinen yöntemler yeterli olmamaktadır. Zaman serilerine ilişkin hata terimlerinde ARCH etkisinin olması durumunda, söz konusu zaman serilerinin tahminlenmesinde otoregresif koşullu değişen varyans modellerinden yararlanılmaktadır.

ARCH-LM testi, oluşturulan modelin hata teriminin farklı varyansa sahip olup olmadığını, diğer bir ifadeyle $\mathrm{ARCH}$ etkisini içerip içermediğini test etmektedir. $a_{t}$ ortalama denklemin artıkları olsun. $a_{t}^{2}$, ARCH etkisi olarak bilinen şartlı değişen varyansı kontrol etmek için kullanılmaktadır. ARCH etkisini belirlemek için iki test mevcuttur. Birinci test, Ljung-Box istatistiği $Q(m)$ 'in $\left\{a_{t}^{2}\right\}$ 'ye uygulanmasıdır. Bu test McLeod ve Li (1983) tarafından geliştirilmiştir. Şartlı farklı varyans için ikinci test Engle (1982)'in Lagrange multiplier testidir. $\mathrm{Bu}$ test, doğrusal regresyondaki $\alpha_{i}=0(i=1, \ldots, m)$ test eden $\mathrm{F}$ istatistiğine karşıllk gelmektedir. Test istatistiği;

$$
F=\frac{\left(S S R_{0}-S S R_{1}\right) / m}{S S R_{1} /(T-2 m-1)}
$$

\footnotetext{
${ }^{1}$ Daha geniş bilgi için bknz. Hamilton (1994), Box ve Jenkins (1970).

${ }^{2}$ Bu modellere ilişkin detaylı bilgi için bknz. Engle (1982), Bollerslev (1986), Nelson (1991), Zakoian (1994), Tse ve Tsui (2002), Engle ve Sheppard (2001), Burns(2005), Silvennoinen ve Terasvirta (2008), Tsay (2011).
} 
$\mathrm{Bu}$ test, asimtotik olarak sıfır hipotezi altında $\mathrm{m}$ serbestlik dereceli ki-kare dağılımı göstermektedir. Eğer $F>\chi_{m}^{2}(\alpha)$ ise sıfır hipotezi reddedilir (Tsay, 2005: 102).

Çalışmada kullanılan yöntemin dayandığı bir model olan ARCH modeli, Engle (1982) tarafindan geliştirilmiştir. Eğer $Y_{t}$ rassal değişkeni $f\left(Y_{t} / Y_{t-1}\right)$ koşullu yoğunluk fonksiyonundan elde ediliyorsa, standart varsayımlar altında, geçmiş bilgiye dayalı olarak oluşturulan bugünkü değerin tahmini $\mathrm{E}\left(\mathrm{Y}_{\mathrm{t}} / \mathrm{Y}_{\mathrm{t}-1}\right)$ varyansı $\mathrm{V}\left(\mathrm{Y}_{\mathrm{t}} / \mathrm{Y}_{\mathrm{t}-1}\right)$ 'dir. Koşullu tahminin varyansı geçmiş bilgiye dayalıdır ve bu nedenle rassal bir değişken olabilir. Bu model otoregresif şartlı değişen varyans $(\mathrm{ARCH})$ modeli olarak adlandırılmaktadır. Bu model, tam olarak bilineer değildir. Normallik varsayımına ilave olarak, bu durum, $\psi_{\mathrm{t}}$ açısından doğrudan açıklanabilir. $\psi_{\mathrm{t}} \mathrm{t}$ zamanında mevcut olan bilgi setidir. Şartlı yoğunlukları kullanarak,

$$
\begin{aligned}
& Y_{t} / \psi_{t} \sim N\left(0, h_{t}\right) \\
& h_{t}=\alpha_{0}+\alpha_{1} Y_{t-1}^{2}
\end{aligned}
$$

Varyans fonksiyonu daha genel olarak aşağıdaki şekilde açıklanabilir:

$$
h_{t}=h\left(Y_{t-1}, Y_{t-2}, \ldots, Y_{t-p}, \alpha\right)
$$

burada $\mathrm{p}, \mathrm{ARCH}$ sürecinin derecesini göstermektedir ve $\alpha$ bilinmeyen parametre vektörüdür.

ARCH regresyon modeli, $Y_{t}$ 'nin ortalamasının $X_{t} \beta$ olduğu varsayılarak elde edilebilir. Burada $X_{t} \beta, \beta$ bilinmeyen parametre vektörü ile $\psi_{t-1}$ bilgi setine dahil olan dışsal değişkenler ile gecikmeli içsel değişkenin doğrusal kombinasyonudur (Engle, 1982: 986-989).

$$
\begin{gathered}
Y_{t} / \psi_{t-1} \sim N\left(X_{t} \beta, h_{t}\right) \\
h_{t}=h\left(e_{t-1}, e_{t-2}, \ldots, e_{t-p}, \alpha\right) \\
e_{t}=Y_{t}-X_{t} \beta \\
h_{t}^{2}=\alpha_{0}+\sum_{i=1}^{p} \alpha_{i} e_{t-i}^{2}
\end{gathered}
$$

$\alpha_{0}>0$ ve $\alpha_{i} \geq 0, i=1, \ldots, p-1$ ve aynı zamanda $\alpha_{p}>0$. Bu şartlar şartlı varyansın her zaman pozitif olmasını sağlamaktadır (Kirchgassner ve Wolters, 2007: 245-246). Diğer bir kısitlama ise $\alpha_{i}$ 'lerin her birinin veya toplamının 1'den küçük olmasıdır. Bu kısıtlama ARCH sürecinin durağanlığının sağlanması için de gereklidir. Tersi durumda süreç sonsuz varyansa sahip olacaktır (Özer ve Türkyılmaz, 2004: 35).

Eğer büyük bir pozitif veya negatif e değeri varsa, bu durum şartlı varyans için büyük değerler serisine yol açar. Eğer meydana gelen şok küçükse, daha küçük şokların yakın gelecekte meydana geleceği varsayılır. p değeri daha yüksek oldukça, oynaklık kümeleri daha geniş olur (Kirchgassner and Wolters, 2007: 246).

ARCH modelinin zayıf yönleri ise aşağıda belirtilmektedir:

1. Model negatif ve pozitif şokların oynaklık üzerinde benzer etkilere sahip olduğunu varsayar. Çünkü model, önceki şokların karesine dayalıdır. Pratikte, finansal varlığın fiyatı pozitif ve negatif şoklara farklı bir şekilde cevap verir.

2. ARCH modeli oldukça sınırlandırıcıdır. 
3. ARCH modeli finansal zaman serilerinin değişkenlik kaynağının anlaşılması için yeni bir anlayış sağlamaz (Tsay, 2005: 103 - 109).

ARCH Modelinin bu zayfilikları nedeniyle Bollerslev (1986) tarafindan GARCH modeli ortaya atılmıştır. ARCH ve GARCH modellerinde anahtar kavram koşullu varyanstır. Klasik GARCH modellerinde koşullu varyans serinin geçmiş dönem değerlerinin karelerinin doğrusal bir fonksiyonudur (Zakoian and Francq, 2010: 19). ARCH modelinin ampirik uygulamalarında, şartlı varyans denkleminde uzun gecikme gerekmektedir ve negatif varyans parametre tahminleri problemini önlemek için sabit bir gecikme yapısından yararlanılması gerekmektedir. ARCH modelinin genişletilmesi hem daha uzun hafizaya hem de daha esnek gecikme yapısına izin vermektedir.

$\mathrm{e}_{\mathrm{t}}$ gerçek değerli kesikli zaman stokastik süreci ve $\psi_{\mathrm{t}} \mathrm{t}$ zamanındaki bilgi setini göstermektedir. GARCH(p,q) süreci aşağıdaki gibi ifade edilmektedir,

$$
\begin{gathered}
e_{t} / \psi_{t-1} \sim N\left(0, h_{t}\right) \\
h_{t}=\alpha_{0}+\sum_{i=1}^{q} \alpha_{i} e_{t-i}^{2}+\sum_{i=1}^{p} \beta_{i} h_{t-i} \\
=\alpha_{0}+A(L) e_{t}^{2}+B(L) h_{t}
\end{gathered}
$$

burada,

$p \geq 0, q>0$

$\alpha_{0}>0, \alpha_{i} \geq 0, i=1, \ldots, q$

$\beta_{i} \geq 0, \quad i=1, \ldots, p$

$p=0$ için, süreç $\mathrm{ARCH}(\mathrm{q})$ sürecine indirgenir, ve $p=q=0$ için $e_{t}$ beyaz gürültülüdür (white noise). $\mathrm{ARCH}(q)$ modelinde şartlı varyans sadece geçmiş örnek varyanslarının doğrusal bir fonksiyonu olarak ifade edilirken, $\operatorname{GARCH}(\mathrm{p}, \mathrm{q})$ süreci aynı zamanda gecikmeli şartlı varyansları da kapsamaktadır (Bollerslev, 1986: 308-309).

$$
V\left(\varepsilon_{t}\right)=E\left[\varepsilon_{t}^{2}\right]=\frac{\alpha_{0}}{1-\alpha(1)-\beta(1)}
$$

$\mathrm{Bu}$ nedenle, GARCH(p,q) sürecinin varyansının var olması için

$$
\alpha(1)+\beta(1)=\sum_{i=1}^{p} \alpha_{i}+\sum_{i=1}^{q} \beta_{i}<1
$$

olmas1 gerekmektedir (Kirchgassner and Wolters, 2007: 252 - 254).

GARCH modelinde, koşullu varyans otokorelasyonlu bir tesadüfi değişkendir ve $e_{t}^{2}$ bir ARMA modeline sahiptir. Aynı zamanda hataların koşulsuz dağılımı simetrik ve sivridir. GARCH modelinin koşulsuz sivriliği, koşulsuz dağılımının kuyruklarındaki ve merkezindeki gözlemlerle birleştirilen düşük oynaklık ve yüksek oynaklık kümelerini gösteren koşullu varyanstaki değişmelerin tekrarlanmasından anlaşılmaktadır. Tüm derecelerdeki koşulsuz momentli, koşullu normal GARCH dağılımı yalnızca $\alpha(\mathrm{L})=\beta(\mathrm{L})=0$ olduğu zaman meydana gelir. Koşullu varyansın yüksek derecede sürekliliği $\alpha$ ve $\beta$ katsayılarının toplamlarının 1'e yakın olmasından kaynaklanmaktadır (Özer ve Türkyılmaz, 2004: 43 - 45).

IGARCH modeli, GARCH modelinde $\alpha_{i}+\beta_{i}=1$ olması durumda, koşullu varyans tahminin kalıcılığını ve hata teriminin koşullu olmayan dağılımının sonsuz varyansa sahip olduğunu ifade etmektedir. Diğger bir ifadeyle, $\alpha_{i}+\beta_{i}=1$ olduğunda, şoklar kalıcıdır. $\mathrm{Bu}$ durumda IGARCH modeli 
kullanılmaktadır. IGARCH modelinde $\varepsilon_{\mathrm{t}},, \alpha_{\mathrm{i}}+\beta_{\mathrm{i}}<1$ olması durumunda kovaryans durağandır. Buna göre volatilitenin fiyatlar üzerindeki anlamlı etkisi, sadece volatilite şoklarının uzun dönemde kalıcı olması durumunda gerçekleşmektedir. Volatilite şoklarının kalıcı olmaması durumunda, piyasa gelecekteki iskonto oranına ilişkin bir düzenleme yapmayacaktır. Diğer bir ifadeyle, volatilite şoklarının geçici olması durumunda, beklenen hisse getirileri volatilite hareketlerinden etkilenmemektedir. $\alpha_{i}$ ve $\beta_{i}$ toplam1 bire ne kadar yakınsa, volatilite şoklarının kalıcılığı o kadar büyük olacaktır (Taufiq, 1995).

EGARCH modeli Nelson (1991) tarafindan geliştirilmiştir. Eğer $\sigma_{\mathrm{t}}^{2} \mathrm{t}$ zamanında verilen bilginin şartlı varyansı ise, pozitif olmak zorundadır. GARCH modeli, bunu $\sigma^{2}$ yi pozitif rassal değişkenlerin doğrusal bir kombinasyonu şeklinde ifade ederek sağlamaktadır. $\sigma^{2}$ 'nin pozitif olmasını sağlamak için diğer bir yöntem, gecikmeli $z_{\mathrm{t}}$ ve zamanın bir fonksiyonu olarak $\ln \left(\sigma_{\mathrm{t}}^{2}\right)$ 'yi doğrusallaştırmaktır.

$$
\ln \left(\sigma_{t}^{2}\right)=\alpha_{t}+\sum_{k=1}^{\infty} \beta_{k} g\left(z_{t-k}\right), \beta_{1} \equiv 1
$$

Burada $z_{t}$ standartlaştırılmış artıktır. EGARCH modeli örneğin borsa getirileri ve oynaklık değişimleri arasındaki asimetrik ilişkiyi ortaya koymaktadır. Bunu sağlamak için, $g\left(z_{t}\right)$ 'nin değeri $z_{t}$ 'nin işaretine ve büyüklüğünün bir fonksiyonu olmak zorundadır. $g\left(z_{t}\right)$, şartlı varyans sürecinin $\left\{\sigma_{t}^{2}\right\}$ hisse senedi fiyatlarındaki artış ve azalışlara asimetrik tepki verilmesine izin vermektedir (Nelson, 1991: 350-351). EGARCH modeli sadece asimetriyi göstermez, aynı zamanda şartlı varyansın her zaman pozitif olmasını da sağlar. EGARCH $(1,1)$ modeli genel olarak aşağıdaki şekilde ifade edilmektedir (Kirchgassner and Wolters, 2007: 257 $-258)$ :

$$
\ln \left(h_{j, t}^{2}\right)=\omega_{j}+\beta_{j} \ln \left(h_{j, t-1}^{2}\right)+\delta \frac{e_{t-1}}{\sqrt{h_{t-1}^{2}}}+\alpha\left[\frac{\left|e_{t-1}\right|}{\sqrt{h_{t-1}^{2}}}-\sqrt{\frac{2}{\pi}}\right]
$$

$\alpha$ parametresi modelin simetrik, yani GARCH etkisini göstermektedir. $\beta$ piyasada meydana gelen herhangi bir şeye bakılmaksızın şartlı oynaklıktaki sürekliliği ölçmektedir. $\beta$ nisbi olarak büyük olduğunda, oynaklığın piyasadaki bir krizi takiben ortadan kalkması (die out) uzun zaman almaktadır. $\delta$ parametresi asimetriyi veya kaldıraç etkisini ölçmektedir. Eğer $\delta=0$ ise, model simetriktir. $\delta<0$ olduğunda, pozitif şoklar (iyi haberler) negatif şoklardan (kötü haberler) daha az oynaklık yaratır. Ĕger $\delta>0$ ise, pozitif değişiklikler negatif değişikliklerden daha çok istikrar bozucudur (Su, 2010: 8-9).

\section{ANALIZZE KULLANILAN DEĞISSKENLER}

Yukarıda belirlenen hipotezlerin testi için analizlerde kullanılacak değişkenler ve bu değişkenlere ilişkin açıklamalar Tablo 1'de gösterilmiştir. 
Sevim Nurbanu Yıldız \& Başak Karşıyakalı \& Üzeyir Aydın / Yeni Para Politikası Yaklaşımı Çerçevesinde Kullanılan Rezerv Opsiyon Mekanizması Etkinliğinin Analizi

Tablo 1: Analizde Kullanılan Değișkenler

\begin{tabular}{|c|c|c|}
\hline Değişkenler & Açıklamalar & Kaynak \\
\hline ROM & $\begin{array}{l}\text { Döviz miktarı için Türk Lirası zorunlu karşılıklar ROM kullanım oranı } \\
\text { ROM Kapsamında Türk Lirası Zorunlu } \\
\qquad R O M=\frac{\text { Karşılıklar İçin Tutulan Döviz Miktarı }}{\text { TCMB Brüt Döviz Rezervi }}\end{array}$ & $\begin{array}{l}\text { TCMB } \\
\text { EVDS }\end{array}$ \\
\hline Enflasyon_tufe & $\begin{array}{l}\text { TÜFE bazlı enflasyon belirsizliği: Literatürde enflasyon belirsizliğinin } \\
\text { ölçülmesinde iki yaklaşım mevcuttur. İlki, bu çalışmada da yapıldığı gibi } \\
\text { geçmiş enflasyon verilerinden hareketle ARCH/GARCH yöntemleri } \\
\text { kullanılarak hata terimleri üzerinden ölçülmesidir (Çidem,2013:29). } \\
\text { İkincisi, beklenen enflasyon ile gerçekleşen enflasyon farkının } \\
\text { alınmasıdır (Samut, 2014:25). }\end{array}$ & $\begin{array}{l}\text { TCMB } \\
\text { EVDS }\end{array}$ \\
\hline Enflasyon_ufe & ÜFE bazlı enflasyon oranı & $\begin{array}{l}\text { TCMB } \\
\text { EVDS }\end{array}$ \\
\hline Kur_sepet & 0.50 (TL/Euro) ve 0.50(TL/USD) döviz kuru & $\begin{array}{l}\text { TCMB } \\
\text { EVDS }\end{array}$ \\
\hline VIX & $\begin{array}{l}\text { VIX endeksi: yatırımcılar tarafından korku endeksi olarak da } \\
\text { adlandırılan VIX endeksinin kullanılması ile uluslararası piyasalardaki } \\
\text { gelişmelerin Türk lirası/ABD doları oynaklığı üzerindeki etkisinin de } \\
\text { analiz edilmesi amaçlanmıştır. }\end{array}$ & $\begin{array}{l}\text { Yahoo } \\
\text { Finance }\end{array}$ \\
\hline Doviz_satilan & $\begin{array}{l}\text { TCMB tarafından satılan döviz miktarı } \\
\text { TCMB'nin müdahaleler veya } \\
\text { Satılan Döviz Miktarı }=\frac{\text { ihaleler yoluyla satığ döviz miktarı }}{\text { TCMB Brüt Döviz Rezervi }}\end{array}$ & $\begin{array}{l}\text { TCMB } \\
\text { EVDS }\end{array}$ \\
\hline Doviz_rezerv & TCMB brüt rezervlerin değişim oranı & $\begin{array}{l}\text { TCMB } \\
\text { EVDS }\end{array}$ \\
\hline Tahvil_faiz & 2 yıllık gösterge tahvil faiz oranı & $\begin{array}{l}\text { TCMB } \\
\text { EVDS }\end{array}$ \\
\hline
\end{tabular}

Analizde kullanılan değişkenler aylık frekansta olup tüm değişkenler, hareketli ortalamalar yöntemi ile mevsimsellikten arındırılmıştır. Aynı zamanda tüm değişkenlerin logaritması alınmıştır. Türkiye Cumhuriyet Merkez Bankası rezerv opsiyon mekanizmasını 2010 yılı sonlarından itibaren yürüttüğünden analize konu olan veriler 2011 Ekim-2018 Aralık dönemini içermektedir. Bu durum çalışmada önemli bir veri kısıtını oluşturmaktadır. Bununla birlikte, literatür incelendiğinde, benzer aylık ve çeyreklik frekansta verileri otoregresif koşullu değişen varyans modelleri ile analiz eden çalışmalara da rastlanılmıştır (Çapar (2010), Erdem (2017)). Değişkenlere ilişkin grafikler aşağıdaki gibidir.

Şekil 1: Değişkenlere Ait Grafikler

Döviz Rezervlerindeki Değişim

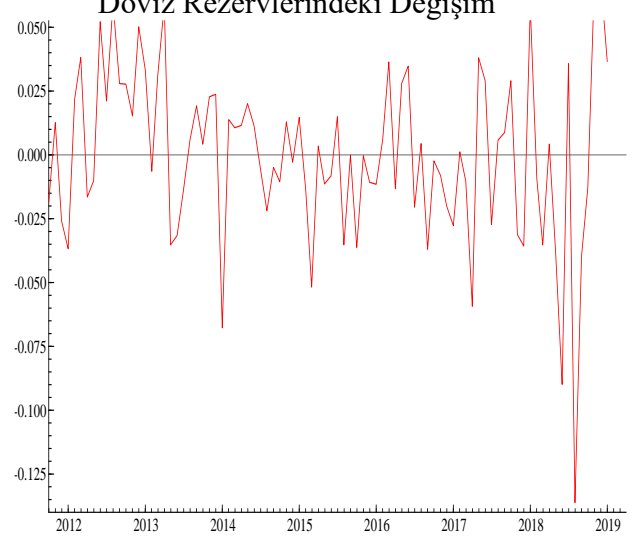

TÜFE Bazlı Enflasyon Belirsizliği

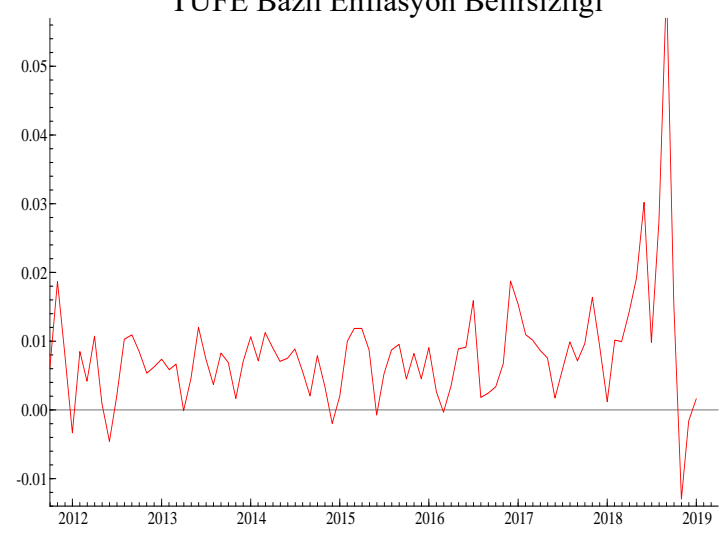




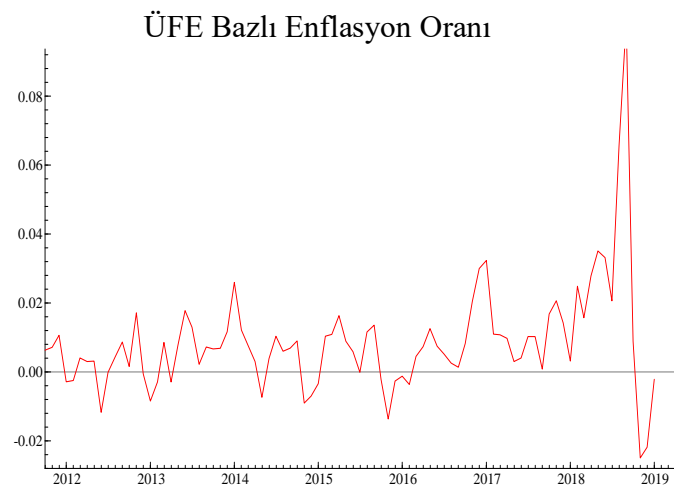

TCMB Tarafından Satılan Döviz Miktarı

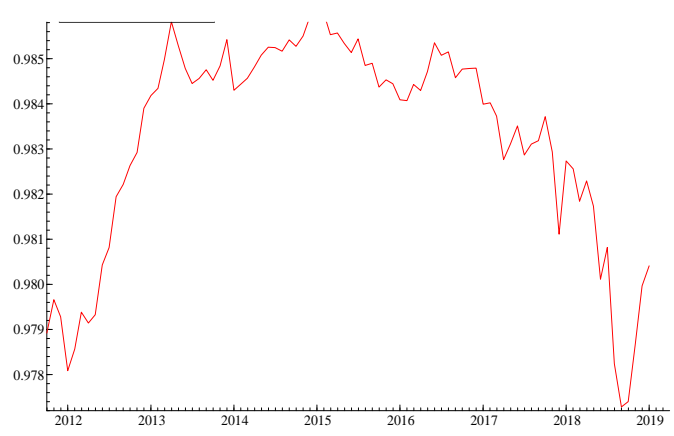

Rezerv Opsiyon Mekanizması Kullanım Oranı

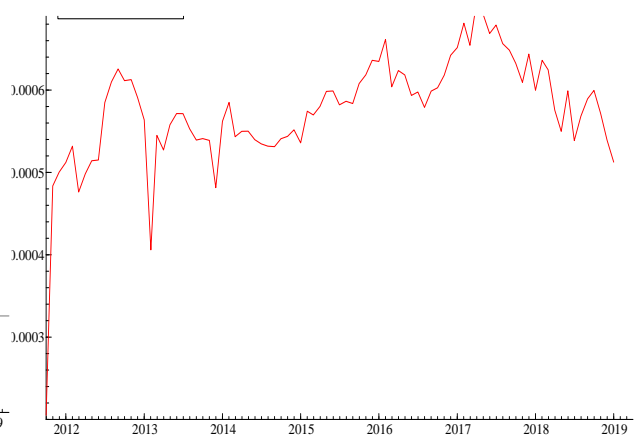

2 yıllık Gösterge Tahvil Faiz Oranı

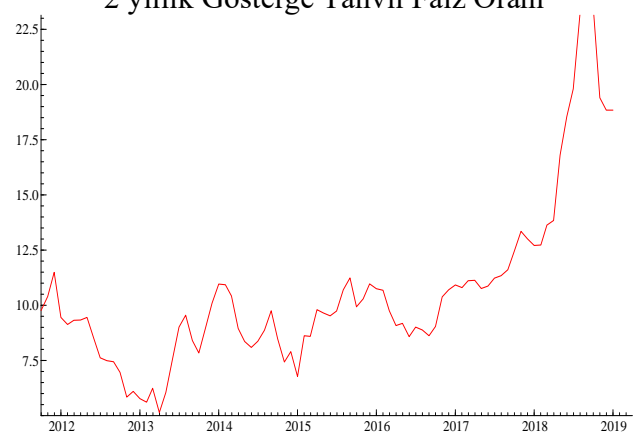

Değişkenlere ait grafikler incelendiğinde döviz rezervlerindeki değişimin çok yüksek olduğu, 2013 yılında satılan döviz miktarının arttı̆̆ daha sonra azalış yönünde bir seyir izlediği görülmektedir. 2018'in ortalarından itibaren yeniden bir artış olmuştur. Gösterge faiz oranı 2013 sonrası yavaş da olsa artış trendine girmiş bu artış yine 2018 ortalarında hızlı bir tırmanış şeklinde gerçekleşmiştir. Enflasyon belirsizliği 2011-2017 yılları arasında yatay bir seyir izlerken 2017 sonrası artış trendine girerek istikrarsızlaşmıştır. Diğer yandan döviz kurlarındaki dalgalanmalara bağlı olarak 2018 yılının ortasından itibaren tüm değişkenlerde oynaklıkların arttı̆̆ı görülmektedir.

\section{AMPIRIK BULGULAR}

Çalışmada ilk olarak değişkenlerin durağanlıkları araştırılmıştır. Ardından amaca bağlı olarak oluşturulan hipotezleri test edebilmek, ROM kullanım oranında meydana gelen negatif ve pozitif şokların analize dahil edilen değişkenler üzerindeki etkisini ölçebilmek, daha uzun hafızayla ve daha esnek gecikme yapısıyla bu değişkenlerdeki değişkenliğin kaynağını ortaya koyabilmek için otoregresif koşullu değişen varyans modellerinden yararlanılmıştır.

\section{A. Durağanlıkların İncelenmesi}

Değişkenlerin durağanlıklarının incelenmesinde, genişletilmiş DickeyFuller (ADF), Phillps-Perron (PP) ve KPSS birim kök testlerinden 
Sevim Nurbanu Yıldız \& Başak Karşıyakalı \& Üzeyir Aydın / Yeni Para Politikası Yaklaşımı Çerçevesinde Kullanılan Rezerv Opsiyon Mekanizması Etkinliğinin Analizi

yararlanılmıştır. Değişkenlere ilişkin birim kök test sonuçları Tablo 2'de yer almaktadir.

Tablo 2: ADF, Phillips-Perron ve KPSS Birim Kök Test Sonuçları

\begin{tabular}{|c|c|c|c|c|c|c|}
\hline & \multicolumn{2}{|c|}{ ADF } & \multicolumn{2}{|c|}{ Phillips-Perron } & \multicolumn{2}{|c|}{ KPSS } \\
\hline Değişkenler & $\begin{array}{c}\text { Sabit } \\
\text { Terimli }\end{array}$ & $\begin{array}{c}\text { Sabit Terim } \\
\text { ve Trendli }\end{array}$ & $\begin{array}{c}\text { Sabit } \\
\text { Terimli }\end{array}$ & $\begin{array}{c}\text { Sabit Terim } \\
\text { ve Trendli }\end{array}$ & $\begin{array}{c}\text { Sabit } \\
\text { Terimli }\end{array}$ & $\begin{array}{c}\text { Sabit Terim } \\
\text { ve Trendli }\end{array}$ \\
\hline ROM & $-3.1902(1)^{* *}$ & $-2.9729(1)$ & $-6.6763(5)^{* * *}$ & $-6.9923(5)^{* * *}$ & $0.7734(6)^{* * * *}$ & $0.1373(5)^{*}$ \\
\hline Enflasyon_tufe & $-4.1646(3)^{* * * *}$ & $-4.7495(3)^{* * * *}$ & $-5.9437(3)^{* * *}$ & $-6.0079(5)^{* * *}$ & $0.4443(3)^{*}$ & $0.0813(1)$ \\
\hline Enflasyon_ufe & $-1.5157(8)$ & $-2.2917(9)$ & $-4.7250(7)^{* * *}$ & $-4.6441(9)^{* * *}$ & $0.5229(3)^{* *}$ & $0.1273(0)^{*}$ \\
\hline Kur_sepet & $-2.6675(7)^{*}$ & $0.4507(7)$ & $0.9378(7)$ & $-1.7086(5)$ & $1.0463(7)^{* * * *}$ & $0.2519(6)^{* * *}$ \\
\hline$\Delta$ Kur_sepet & $-4.4595(3)^{* * * *}$ & $-4.9654(3)^{* * * *}$ & $-5.7638(3)^{* *}$ & $-6.4749(3)^{* * * *}$ & $0.2736(5)$ & $0.0494(8)$ \\
\hline VIX & $-5.8299(0)^{* * * *}$ & $-5.8935(0)^{* * * *}$ & $-5.7365(1)^{* * *}$ & $-5.7954(1)^{* * *}$ & $0.3111(5)$ & $0.1109(5)$ \\
\hline Doviz_satilan & $-1.7228(0)$ & $-1.8534(0)$ & $-1.8163(4)$ & $-1.8359(2)$ & $0.2737(7)$ & $0.2671(7)$ \\
\hline$\Delta$ Doviz_satilan & $-8.8901(0)^{* * * *}$ & $-9.1986(0)^{* * * *}$ & $-8.9134(4)^{* * * *}$ & $-9.1990(1)^{* * * *}$ & $0.3377(4)$ & $0.0391(1)$ \\
\hline Doviz_rezerv & $-8.2213(0)^{* * *}$ & $-8.4898(0)^{* * *}$ & $-8.3098(4)^{* * * *}$ & $-8.4876(4)^{* * * *}$ & $0.3079(4)$ & $0.0508(3)$ \\
\hline Tahvil_faiz & $-0.6324(0)$ & $-2.8015(1)$ & $-0.7832(1)$ & $-2.4445(2)$ & $0.7926(7)^{* * * *}$ & $0.1652(6)^{* * *}$ \\
\hline$\Delta$ Tahvil_faiz & $-8.0173(0)^{* * *}$ & $-8.1262(0)^{\text {*** }}$ & $-8.0006(3)^{* * * *}$ & $-8.0597(5)^{* * * *}$ & $0.1568(2)$ & $0.0392(4)$ \\
\hline \multirow{3}{*}{ Kritik Değerler } & $\% 1-3.50$ & $\% 1-4.06$ & $\% 1 \quad-3.50$ & $\% 1 \quad-4.06$ & $\% 1 \quad 0.73$ & 0.21 \\
\hline & $\% 5 \quad-2.89$ & $\% 5 \quad-3.46$ & $\% 5 \quad-2.89$ & $\% 5 \quad-3.46$ & 0.46 & 0.14 \\
\hline & $\begin{array}{ll}\% 10 & -2.58\end{array}$ & $\% 10 \quad-3.15$ & $\% 10 \quad-2.58$ & -3.15 & $\% 10$ & $\% 10$ \\
\hline
\end{tabular}

Not: $* * *, * * *$ surasıly $\% 1, \% 5$ ve \%10 önem seviyelerinde anlamlılıkları göstermektedir. Parantez içindeki değerler gecikme uzunluklarını göstermektedir. $\Delta$ ise değişkenin birinci farkının alındığını ifade etmektedir.

Sabit terimli birim kök test sonuçları incelendiğinde, ADF birim kök testine göre ROM, Enflasyon_tufe, Kur_sepet, VIX, Doviz_satilan, Doviz_rezerv değişkenlerinin \%10 önem seviyesinde düzey değerlerinde durağan oldukları görülmektedir. Buna karşın, Enflasyon_ufe değişkeni birinci farkında durağan hale gelmektedir. Phillips-Perron birim kök test sonucuna göre, ROM, Enflasyon_tufe, Enflasyon_ufe, VIX ve Doviz_rezerv değişkenlerinin düzey değerlerinde; Doviz_satilan ve Kur_sepet değişkenlerinin ise birinci farklarında durağan oldukları ifade edilebilir. KPSS birim kök test sonucuna göre ise, Doviz_rezerv, Doviz_satilan, VIX değişkenlerinin düzey değerlerinde; ROM, Enflasyon_tufe, Enflasyon_ufe ve Kur_sepet değişkenlerinin birinci farklarında durağan hale geldiği görülmektedir.

Tablo 2'de yer alan sabit terim ve trendli birim kök test sonuçları incelendiğinde, ADF birim kök testine göre Enflasyon_tufe, VIX ve Doviz_rezerv değişkenlerinin düzey değerlerinde, ROM, Enflasyon_ufe, Kur_sepet, Doviz_satilan değişkenlerinin ise birinci farklarında durağan oldukları ifade edilmektedir. Phillips-Perron birim kök test sonucuna göre ise, ROM, Enflasyon_ufe, Enflasyon_tufe, VIX, Doviz_rezerv değişkenleri düzey değerlerinde; Kur_sepet ve Doviz_satilan değişkenleri birinci farklarında durağandır. KPSS testi dikkate alındığında, Enflasyon_tufe, VIX, Doviz_rezerv, Doviz_satilan değişkenlerinin düzey değerlerinde, ROM, Enflasyon_ufe, 
Tahvil_faiz ve Kur_sepet değişkenleri birinci farklarında durağan hale geldiği görülmektedir. Gerek ADF, Phillips-Perron ve KPSS birim kök test sonuçlarının birbirine benzer sonuçlar vermemesi, gerekse ele alınan dönemin politik, jeopolitik ve finansal şokları içermesi nedeniyle, değişkenlerin durağanlıkları aynı zamanda Zivot-Andrews testi ile de incelenmiştir.

Zivot-Andrews birim kök test sonuçları Tablo 3'de gösterilmektedir. Buna göre, sabit terimli birim kök testine göre Enflasyon_tufe, Enflasyon_ufe, VIX, Doviz rezerv değişkenlerinin düzey değerlerinde; buna karşın, ROM, Kur_sepet, Doviz_satilan değişkenlerinin birinci farklarında durağan oldukları ifade edilebilir. Trendli birim kök testine göre, ROM, Enflasyon_ufe, Enflasyon_tufe, Kur_sepet, VIX ve Doviz_rezerv değişkenleri düzeyde, Doviz_satilan ve Tahvil_faiz değişkenleri ise birinci farkında durağandır. Son olarak, sabit terim ve trendli test sonuçlarına göre, ROM, Enflasyon_tufe, Enflasyon_ufe, VIX, Doviz_rezerv değişkenleri düzey değerlerinde durağan iken, Kur_sepet ve Doviz_satilan değişkenleri birinci farklarında durağan olduğu görülmektedir.

Tablo 3: Zivot-Andrews Birim Kök Test Sonuçları

\begin{tabular}{|c|c|c|c|c|c|c|}
\hline Değişkenler & $\begin{array}{c}\text { Sabit } \\
\text { Terimli }\end{array}$ & $\begin{array}{c}\text { KIrılma } \\
\text { Tarihi }\end{array}$ & Trendli & $\begin{array}{c}\text { KIrılma } \\
\text { Tarihi }\end{array}$ & $\begin{array}{c}\text { Sabit Terim } \\
\text { ve Trendli }\end{array}$ & $\begin{array}{c}\text { Kirılma } \\
\text { Tarihi }\end{array}$ \\
\hline ROM & $-3.8558(1)$ & 2017 M11 & $-4.4294(1)^{* *}$ & 2017 M8 & $-4.9087(1)^{*}$ & 2016 M12 \\
\hline Enflasyon_tufe & $-5.3124(3)^{* * *}$ & 2017 M11 & $-5.3633(3)^{* * *}$ & 2016 M9 & $-5.4533(3)^{* * *}$ & 2016 M2 \\
\hline Enflasyon_ufe & $-6.9235(1)^{* * *}$ & 2017 M10 & $-6.7993(1)^{* * *}$ & 2016 M12 & $-6.8882(1)^{* * * *}$ & 2015 M10 \\
\hline Kur_sepet & $-3.4441(3)$ & 2017 M10 & $-4.998(3)^{* *}$ & 2017 M7 & $-4.6571(3)$ & 2017 M4 \\
\hline$\Delta$ Kur_sepet & $-5.3193(3)^{* * *}$ & 2017 M10 & $-5.1103(3)^{* * *}$ & 2016 M7 & $-5.2341(3)^{* * *}$ & $2015 \mathrm{M} 10$ \\
\hline VIX & $-5.3588(1)^{* *}$ & 2017 M12 & $-5.4939(1)^{* * *}$ & 2017 M10 & $-5.9025(1)^{* * *}$ & 2017 M1 \\
\hline Doviz_satilan & $-2.6106(0)$ & 2013 M1 & $-3.3127(0)$ & 2013 M1 & $-2.6118(0)$ & 2013 M1 \\
\hline$\Delta$ Doviz_satilan & $-9.4359(0)^{* * * *}$ & 2013 M5 & $-9.2597(0)^{* * * *}$ & 2017 M11 & $-9.7058(0)^{* * * *}$ & 2013 M5 \\
\hline Doviz_rezerv & $-8.8136(0)^{* * *}$ & 2013 M5 & $-8.5434(0)^{* * *}$ & 2017 M12 & $-9.1058(0)^{* * *}$ & 2013 M5 \\
\hline Tahvil_faiz & $-33.4667(1)$ & 2017 M10 & $-3.5484(1)$ & 2017 M5 & $-3.7200(1)$ & 2016 M3 \\
\hline$\Delta$ Tahvil_faiz & $-8.4414(0)^{* * * *}$ & 2013 M5 & $-8.2270(0)^{* * * *}$ & 2013 M7 & $-8.4804(0)^{* * * *}$ & $2014 \mathrm{M} 2$ \\
\hline \multirow{3}{*}{ Kritik Değerler } & $\% 1$ & -5.34 & $\% 1$ & -4.80 & $\% 1$ & -5.57 \\
\hline & $\% 5$ & -4.93 & $\% 5$ & -4.42 & $\% 5$ & -5.08 \\
\hline & $\% 10$ & -4.58 & $\% 10$ & -4.11 & $\% 10$ & -4.82 \\
\hline
\end{tabular}

Not: ***,*** sırasıly \%1, \%5 ve \%10 önem seviyelerinde anlamlılıkları göstermektedir. Parantez içindeki değerler gecikme uzunluklarını göstermektedir. $\Delta$ değişkenin birinci farkının alındığını ifade etmektedir.

\section{B. ROM'un Döviz Rezervleri Volatilitesi Üzerine Etkisi}

ROM'un döviz rezervleri volatilitesi üzerine etkisini incelemek amaciyla, ilk olarak ortalama ARMA modeli oluşturulmuş ve bu modelin volatilite yapısına sahip olup olmadığı ortaya konulmuştur. Bilgi kriterleri ve katsayıların anlamlılıkları dikkate alındığında döviz rezervlerindeki değişim için ARMA(2,0) modeli en uygun model olarak belirlenmiştir. Model tahmin sonucu ve ARCHLM test sonucu Tablo 4'de gösterilmektedir. 
Sevim Nurbanu Yıldız \& Başak Karşıyakalı \& Üzeyir Aydın / Yeni Para Politikası Yaklaşımı Çerçevesinde Kullanılan Rezerv Opsiyon Mekanizması Etkinliğinin Analizi

Tablo 4: Döviz Rezervindeki Değişime İlişkin ARMA(2,0) Model Tahmin Sonucu

\begin{tabular}{|c|c|c|c|c|}
\hline Değişkenler & Katsayı & Standart Hata & t-İstatistiği & Prob. \\
\hline $\mathrm{C}$ & 0.000519 & $1.22 \mathrm{E}-05$ & 4.249 .813 & 0.0000 \\
\hline $\mathrm{AR}(1)$ & 1.201 .266 & 0.098850 & 1.215 .240 & 0.0000 \\
\hline $\mathrm{AR}(2)$ & -0.354359 & 0.099294 & -3.568 .790 & 0.0006 \\
\hline SIGMASQ & $3.02 \mathrm{E}-10$ & $4.53 \mathrm{E}-11$ & 6.672 .274 & 0.0000 \\
\hline R-kare & 0.815866 & \multicolumn{2}{|c|}{ Akaike bilgi kriteri } & -1.895 .535 \\
\hline Düzeltilmiş R-kare & 0.808401 & \multicolumn{2}{|c|}{ Schwarz bilgi kriteri } & -1.883 .449 \\
\hline Log likelihood & 7.432 .587 & \multicolumn{2}{|c|}{ Hannan-Quinn bilgi kriteri } & -1.890 .697 \\
\hline F-istatistiği & 1.092 .939 & \multicolumn{2}{|c|}{ Durbin-Watson stat } & 2.047 .518 \\
\hline \multicolumn{5}{|c|}{ Farklı Varyans Testi: ARCH-LM testi } \\
\hline F-istatistiği & 5.206 .513 & \multicolumn{2}{|c|}{ Prob. $\mathrm{F}(2,73)$} & 0.0077 \\
\hline Gözlem sayıs1*R-kare & 9.487 .607 & \multicolumn{2}{|c|}{ Prob. Ki-kare(2) } & 0.0087 \\
\hline
\end{tabular}

Uygun modelin belirlenmesinin ardından, söz konusu modelin volatilite yapısına sahip olup olmadığını belirlemek amacıyla ARCH-LM testi yapılmıştır. ARCH-LM testinde sıfir hipotezi söz konusu zaman serisinde ARCH etkisinin olmadığını, alternatif hipotez ise olduğunu belirtmektedir. ARCH-LM test sonucu incelendiğinde, $\mathrm{F}$ istatistiğine ilişkin olasılık değerinin (0.0077) 0.05 'den küçük olması nedeniyle sıfır hipotezi reddedilmiştir. Dolayısıyla döviz rezervindeki değişimde ARCH etkisi vardır.

Modelde ARCH etkisinin tespit edilmesinin ardından, döviz rezervlerindeki değişimin volatilite yapısının ortaya konulması amacıyla otoregresif koşullu değişen varyans modelinden yararlanılmıştır. $\mathrm{Bu}$ amaçla alternatif otoregresif koşullu değişen varyans modelleri $(\mathrm{GARCH}, \mathrm{EGARCH}$, TGARCH vb.) denenmiştir. Model parametrelerinin istatistiki anlamlılıkları, Akaike (AIC) ve Scwartz (SC) bilgi kriterlerine göre en uygun model olarak IGARCH $(1,1)$ modeli belirlenmiştir. Yukarıda da ifade edildiği gibi IGARCH modeli, GARCH modelinde ARCH ve GARCH parametrelerinin toplamının 1'e eşit olması durumunu ifade etmektedir. Model tahmin sonucu ve ARCH-LM test sonucu Tablo 5'de yer almaktadir.

Tablo 5: Döviz Rezervlerindeki Değișime İlişkin IGARCH(1,1) Model Tahmin Sonucu

\begin{tabular}{|c|c|c|c|c|}
\hline Değişkenler & Katsayı & Standart Hata & t-İstatistiği & Prob. \\
\hline ARCH & 0.156867 & 0.095041 & 1.650 .523 & 0.0988 \\
\hline GARCH(-1) & 0.843133 & 0.095041 & 8.871 .298 & 0.0000 \\
\hline ROM & 0.069327 & 0.062831 & 1.103 .382 & 0.2699 \\
\hline GED PARAMETER & 1.780 .315 & 0.517423 & 3.440 .736 & 0.0006 \\
\hline Akaike bilgi kriteri & -3.971 .208 & Log likelihood & 1.787 .331 \\
\hline Schwarz bilgi kriteri & -3.858 .601 & Hannan-Quinn kriteri & -3.925 .841 \\
\hline \multicolumn{4}{|c|}{ Farklı Varyans Testi: ARCH-LM testi } \\
\hline F-istatistiği & 1.098 .710 & \multicolumn{2}{c|}{ Prob. F(2,73) } & 0.3381 \\
\hline Gözlem sayısi*R-kare & 2.218 .120 & \multicolumn{2}{|c|}{ Probi-kare(2) } & 0.3299 \\
\hline
\end{tabular}

Tablo 5'te ARCH-LM test sonucu incelendiğinde, $\mathrm{F}$ istatistiğine ilişkin olasıl1k değerinin (0.3381) 0.05'den büyük olması nedeniyle ARCH etkisinin olmadığını söyleyen sıfır hipotezinin reddedilemediği görülmektedir. Bu durum, oluşturulan IGARCH(1,1) modelinde ARCH etkisinin ortadan kalktığını ifade etmektedir. Tablo 5'deki model sonuçlarına göre; TCMB döviz rezervlerindeki değişim parametresindeki şokların etkisinin uzun dönemde ortadan kalkmadığ 1 , diğer bir ifadeyle şokların etkisinin kalıcı olduğu ifade edilebilir. Dolayısıyla, 
ROM, TCMB döviz rezervlerindeki değişim volatilitesi üzerinde anlamlı bir etkiye sahip değildir.

\section{ROM'un Enflasyon Belirsizliği ve Enflasyon Oranı Üzerine Etkisi}

ROM'un enflasyon belirsizliği ve enflasyon oranı üzerindeki etkisini incelemek amacıyla, ilk olarak TÜFE enflasyon belirsizliği ve ÜFE enflasyon oranına ilişkin uygun ortalama ARMA modeli belirlenmiştir. Uygun gecikme uzunluklarının belirlenmesinde, katsayıların anlamlılıkları ile AIC ve SC bilgi kriterleri dikkate alınmıştır. Bu kapsamda, TÜFE enflasyon belirsizliği ve ÜFE bazlı enflasyon oranları için uygun ARMA modelleri sırasıyla $\operatorname{ARMA}(0,1)$ ve ARMA(1,1) olarak belirlenmiştir. Model tahmin sonuçları ve ARCH-LM test sonuçları Tablo 6 ve Tablo 7'de yer almaktadır.

Tablo 6: TÜFE Enflasyon Belirsizliği İçin ARMA $(0,1)$ Model Tahmin Sonucu

\begin{tabular}{|c|c|c|c|c|}
\hline Değişkenler & Katsayı & Standart Hata & t-İstatistiği & Prob. \\
\hline C & 0.008384 & 0.001757 & 4.771338 & 0.0000 \\
\hline MA(1) & 0.700379 & 0.034862 & 20.08996 & 0.0000 \\
\hline SIGMASQ & $5.11 \mathrm{E}-05$ & $5.08 \mathrm{E}-06$ & 10.06290 & 0.0000 \\
\hline R-kare & 0.305106 & Akaike bilgi kriteri & -6.958794 \\
\hline Düzeltilmiş R-kare & 0.286575 & Schwarz bilgi kriteri & -6.868152 \\
\hline Log likelihood & 274.3930 & Hannan-Quinn kriteri & -6.922508 \\
\hline F-istatistiği & 16.46503 & Durbin-Watson istatistiği & 2.065235 \\
\hline \multicolumn{7}{|c|}{ Farklı Varyans Testi: ARCH-LM testi } \\
\hline F-istatistiği & 2.061 .750 & \multicolumn{2}{c|}{ Prob. F(2,73) } & 0.0000 \\
\hline Gözlem sayı1*R-kare & 2.743 .345 & Prob. Ki-kare(2) & 0.0000 \\
\hline
\end{tabular}

Tablo 6'ya göre, TÜFE enflasyon belirsizliği için tahmin edilen $\operatorname{ARMA}(0,1)$ modelinden elde edilen MA(1) katsayısı 0.700379 ve olasılık değeri 0.0000 olarak bulunmuştur. Dolayısıyla, bir dönem önceki şokun cari dönemde TÜFE enflasyon belirsizliğini arttırıcı bir etkiye sahip olduğu söylenebilir.

ARCH-LM test sonucu $\mathrm{F}$ istatistiğine ilişkin olasılık değeri (0.0000) 0.05 'den küçük olması nedeniyle zaman serisinde ARCH etkisinin olmadığını söyleyen sıfır hipotezi reddedilmektedir. Bu durum, TÜFE enflasyon belirsizliği için oluşturulan ARMA modellerinde ARCH etkisinin varlı̆̆ını göstermektedir.

Tablo 7: ÜFE Bazlı Enflasyon Oranı İçin ARMA $(1,1)$ Model Tahmin Sonucu

\begin{tabular}{|c|c|c|c|c|}
\hline Değişkenler & Katsayı & Standart Hata & t-İstatistiği & Prob. \\
\hline C & 0.008617 & 0.003911 & 2.203 .372 & 0.0303 \\
\hline AR(1) & 0.259893 & 0.093973 & 2.765 .630 & 0.0070 \\
\hline MA(1) & 0.470641 & 0.106957 & 4.400 .301 & 0.0000 \\
\hline SIGMASQ & 0.000159 & $1.40 \mathrm{E}-05$ & 1.133 .901 & 0.0000 \\
\hline R-kare & 0.369588 & \multicolumn{2}{|c|}{ Akaike bilgi kriteri } & -5.810 .478 \\
\hline Düzeltilmiş R-kare & 0.347073 & \multicolumn{2}{|c|}{ Schwarz bilgi kriteri } & -5.697 .871 \\
\hline Log likelihood & 2.596 .610 & \multicolumn{2}{c|}{ Hannan-Quinn kritieri } & -5.765 .111 \\
\hline F-istatistiği & 1.641 .539 & \multicolumn{2}{c|}{ Durbin-Watson istatistiği } & 1.956 .425 \\
\hline \multicolumn{5}{|c|}{ Farklı Varyans Testi: ARCH-LM testi } \\
\hline F-istatistiği & 2.924 .723 & \multicolumn{2}{|c|}{ Prob. F(2,73) } & 0.0000 \\
\hline Gözlem sayısı*R-kare & 3.555 .280 & \multicolumn{2}{c|}{ Prob. Ki-kare(2) } & 0.0000 \\
\hline
\end{tabular}

Tablo 7'de yer alan ÜFE bazlı enflasyon oranı için ARMA(1,1) model tahmin sonucuna göre, AR(1) katsayısı 0.259893 ve olasılık değeri 0.0000 olarak elde edilmiştir. Bu durum, bir önceki dönemde ÜFE bazlı enflasyon oranında meydana gelen artışın cari dönemdeki değerini arttırdığını göstermektedir. Ayrıca, MA(1) katsayısının da pozitif ve 0.05 önem seviyesinde istatistiksel 
olarak anlamlı bulunması, bir önceki dönemde meydana gelen şokun cari dönemde ÜFE bazlı enflasyon oranını arttırıcı bir etki yaptığını ifade etmektedir.

ARCH-LM test sonucu F istatistiğine ilişkin olasılık değeri (0.0000) 0.05 'den küçük olması nedeniyle zaman serisinde ARCH etkisinin olmadığını söyleyen sıfır hipotezi reddedilmektedir. Bu durum, ÜFE bazlı enflasyon oranları için oluşturulan ARMA modellerinde ARCH etkisinin varlığını göstermektedir.

TÜFE enflasyon belirsizliği ve ÜFE bazlı enflasyon oranları için oluşturulan ARMA modellerinde ARCH etkisinin tespit edilmesinin ardından, volatilite yapısının ortaya konulması amacıyla otoregresif koşullu değişen varyans modelinden yararlanılmıştır. Alternatif otoregresif koşullu değişen varyans modelleri (GARCH, EGARCH, TGARCH vb.) denenmiş, parametrelerin anlamlılıkları ve minimum AIC ve SC bilgi kriterlerine göre TÜFE ve ÜFE bazlı enflasyon oranları için en uygun koşullu değişen varyans modelleri olarak IGARCH(1,1) modeli belirlenmiştir. Model tahmin sonuçları ve ARCH-LM test sonuçları sırasıyla Tablo 8 ve Tablo 9'da yer almaktadır.

Tablo 8: TÜFE Enflasyon Belirsizliği İçin IGARCH(1,1) Model Tahmin Sonucu

\begin{tabular}{|c|c|c|c|c|}
\hline Değişkenler & Katsayı & Standart Hata & t-İstatistiği & Prob. \\
\hline ARCH & 0.324147 & 0.180160 & 1.799 .214 & 0.0720 \\
\hline GARCH(-1) & 0.675853 & 0.180160 & 3.751 .401 & 0.0002 \\
\hline ROM & 0.004038 & 0.003491 & 1.156 .585 & 0.2474 \\
\hline GED PARAMETER & 1.223 .579 & 0.313926 & 3.897 .666 & 0.0001 \\
\hline Akaike bilgi kriteri & -7.677 .213 & Log likelihood & 3.044 .113 \\
\hline Schwarz bilgi kriteri & -7.526 .142 & Hannan-Quinn kriteri & -7.616 .736 \\
\hline \multicolumn{5}{|c|}{ Farklı Varyans Testi: ARCH-LM testi } \\
\hline F-istatistiği & 0.130803 & Prob. F(2,73) & 0.8776 \\
\hline Gözlem sayıs1*R-kare & 0.271384 & Prob. Ki-kare(2) & 0.8731 \\
\hline
\end{tabular}

Tablo 8 ve Tablo 9'daki sonuçlar incelendiğinde, TÜFE enflasyon belirsizliği ve ÜFE bazlı enflasyon oranlarında meydana gelen şokların uzun süre etkisini gösterdiği ve şokların kalıcı olduğu ifade edilebilir. ROM'un TÜFE enflasyon belirsizliği ve ÜFE bazlı enflasyon oranı üzerindeki etkileri dikkate alındığında ise söz konusu parametreler üzerinde anlamlı bir etkiye sahip olmadığ1 görülmektedir. Tablo 8 ve 9'daki ARCH-LM F istatistiğine göre, he iki değişken için IGARCH( 1,1$)$ modellerinde ARCH etkisi ortadan kalkmaktadır.

Tablo 9: ÜFE Bazlı Enflasyon Oranı İçin IGARCH(1,1) Model Tahmin Sonucu

\begin{tabular}{|c|c|c|c|c|}
\hline Değişkenler & Katsayı & Standart Hata & t-İstatistiği & Prob. \\
\hline ARCH & 0.252273 & 0.121080 & 2.083 .523 & 0.0538 \\
\hline GARCH(-1) & 0.747727 & 0.221080 & 3.382 .151 & 0.0007 \\
\hline ROM & 0.017874 & 0.021477 & 0.832245 & 0.4053 \\
\hline GED PARAMETER & 1.015 .459 & 0.231664 & 4.383 .333 & 0.0000 \\
\hline Akaike bilgi kriteri & -6.370 .270 & Log likelihood & 2.862 .919 \\
\hline Schwarz bilgi kriteri & -6.201 .361 & Hannan-Quinn kriteri & -6.302 .221 \\
\hline \multicolumn{7}{|c|}{ Farklı Varyans Testi: ARCH-LM testi } \\
\hline F-istatistiği & 0.379737 & Prob. F(2,73) & 0.6852 \\
\hline Gözlem sayıs1*R-kare & 0.779789 & Prob. Ki-kare(2) & 0.6771 \\
\hline
\end{tabular}

\section{Döviz Kuru Değişimini Etkileyen Faktörlerin ve ROM'un Döviz Kurları Volatilitesi Üzerindeki Etkisinin Analizi}

ROM'un sepet döviz kur volatilitesi üzerindeki etkisini analiz edebilmek amacıyla ilk olarak, döviz sepetine ilişkin uygun ARMA modeli belirlenmiştir. 
Katsayıların anlamlı olduğu ve minimum AIC ve SC bilgi kriterlerine sahip en uygun ARMA modeli, ARMA $(0,1)$ olarak belirlenmiştir. Model tahmin sonuçları ve ARCH-LM test sonuçları Tablo 10'da yer almaktadır.

Tablo 10: Sepet Döviz Kur İçin Olușturulan ARMA $(0,1)$ Modeline İlișkin Tahmin Sonuçları

\begin{tabular}{|c|c|c|c|c|}
\hline Değiş̧kenler & Katsayı & Standart Hata & t-İstatistiği & Prob. \\
\hline C & 0.010911 & 0.005743 & 1.899 .789 & 0.0609 \\
\hline MA(1) & 0.505777 & 0.103763 & 4.874 .356 & 0.0000 \\
\hline SIGMASQ & 0.001004 & $8.44 \mathrm{E}-05$ & 1.189 .295 & 0.0000 \\
\hline R-kare & 0.195393 & Akaike bilgi kriteri & -3.993 .789 \\
\hline Düzeltilmiş R-kare & 0.176236 & Schwarz bilgi kriteri & -3.908 .758 \\
\hline Log likelihood & 1.767 .298 & Hannan-Quinn kriteri & -3.959 .550 \\
\hline F-istatistiği & 1.019 .940 & Durbin-Watson istatistiği & 2.022 .018 \\
\hline \multicolumn{5}{|c|}{ Farklı Varyans Testi: ARCH-LM testi } \\
\hline F-istatistiği & 4.910 .033 & \multicolumn{2}{|c|}{ Prob. F(2,73) } & 0.0097 \\
\hline Gözlem sayısı*R-kare & 9.090 .667 & Prob. Ki-kare(2) & 0.0106 \\
\hline
\end{tabular}

Tablo 10'a göre, MA(1) katsayıs1 pozitif ve 0.10 önem seviyesinde istatistiksel olarak anlamlı bulunmuştur. Dolayısıyla, bir önceki dönem meydana gelen şok, cari dönemde sepet döviz kurunu yükseltmektedir.

Uygun modelin belirlenmesinin ardindan, sepet döviz kur için oluşturulan ARMA $(0,1)$ modeline ilişkin olarak yapılan ARCH-LM testine ait F istatistiğinin olasılık değerinin (0.0097) 0.05'den küçük olduğu Tablo 10'dan izlenebilmektedir. Buna göre ARCH etkisinin olmadığını söyleyen sıfır hipotezi reddedilmektedir. $\mathrm{Bu}$ durum modelin $\mathrm{ARCH}$ etkisi içerdiğini ifade etmektedir. $\mathrm{Bu}$ nedenle modellemeye, koşullu değişen varyans modeli ile devam edilmiştir. ROM'un sepet döviz kur volatilitesi üzerindeki etkisini ortaya koymak için alternatif koşullu değişen varyans modelleri test edilmiş ve parametrelerin anlamlı olduğu ve minimum AIC ve SC bilgi kriterlerine sahip en uygun koşullu değişen varyans modeli olarak EGARCH(1,1) modeli belirlenmiştir. Model tahmin sonucu Tablo 11'de yer almaktadır.

Tablo 11: Sepet Döviz Kuru İçin Oluşturulan EGARCH(1,1) Model Tahmin Sonucu

\begin{tabular}{|c|c|c|c|c|}
\hline \multicolumn{5}{|c|}{ Ortalama Denklemi } \\
\hline Değişkenler & Katsayı & Standart Hata & t-İstatistiği & Prob. \\
\hline ROMIDOVIZSA & -4.492 .366 & 2.090 .373 & -2.149 .074 & 0.0316 \\
\hline DSATILANDOVIZSA & -1.470 .618 & 2.813 .007 & -5.227 .920 & 0.0000 \\
\hline DTAHVIL_FAIZ & 0.129232 & 0.013267 & 9.740 .834 & 0.0000 \\
\hline VIXSA & -0.000204 & 0.000447 & -0.456375 & 0.6481 \\
\hline C & 0.049290 & 0.008946 & 5.509 .945 & 0.0000 \\
\hline MA(1) & 0.431463 & 0.064243 & 6.716 .107 & 0.0000 \\
\hline \multicolumn{5}{|c|}{ Varyans Denklemi } \\
\hline Değișkenler & Katsayı & Standart Hata & t-İstatistiği & Prob. \\
\hline C & 0.943083 & 0.003417 & 2.759 .606 & 0.0000 \\
\hline Asimetri Etkisi & -0.763906 & 0.087087 & -8.771 .783 & 0.0000 \\
\hline ARCH & 0.447469 & 0.044979 & 9.948 .343 & 0.0000 \\
\hline GARCH(-1) & 0.777795 & $1.9 E-104$ & $4.1 E+103$ & 0.0000 \\
\hline ROM & -0.027391 & 0.015333 & -1.786 .418 & 0.0740 \\
\hline GED PARAMETER & 1.443 .666 & 0.430335 & 3.354 .750 & 0.0008 \\
\hline Akaike bilgi kriteri & -4.335 .814 & Log likelihood & 1.966 .079 \\
\hline Schwarz bilgi kriteri & -4.109 .064 & Hannan-Quinn kriteri & -4.244 .509 \\
\hline \multicolumn{7}{|c|}{ Farklı Varyans Testi: ARCH-LM testi } \\
\hline F-istatistiği & 0.062782 & Prob. F(2,73) & 0.9392 \\
\hline Gözlem sayis1*R-kare & 0.129958 & Prob. Ki-kare(2) & 0.9371 \\
\hline
\end{tabular}


Tablo 11'e göre şu değerlendirmeleri yapmak mümkündür: ROM'da meydana gelen artışlar sepet döviz kur seviyesinin anlamlı bir şekilde azalmasına neden olmaktadır. Benzer şekilde, TCMB tarafından satılan döviz miktarı arttıkça, sepet döviz kuru azalmaktadır. Diğer yandan 2 yıllık tahvil faiz oranındaki artışlar ise sepet döviz kur seviyesi üzerinde pozitif etkiye sahiptir. Buna karşın, VIX endeksinin sepet döviz kuru üzerinde anlamlı bir etkiye sahip olmadığı görülmektedir. Varyans denklemi incelendiğinde ise, ROM'un döviz sepeti volatilitesini azaltıcı yönde bir etki yaptı̆̆ı ifade edilebilir. Aynı zamanda, modelde asimetri etkisi dikkate alındığında, negatif haberlerin döviz kur sepeti volatilitesi üzerindeki etkisinin pozitif haberlere göre daha yüksek olduğu görülmektedir. Modelde ARCH-LM test sonuçlarına göre de ARCH etkisi ortadan kalkmaktadır.

\section{SONUÇ}

Çalışmada, 2011 Ekim-2018 Aralık dönemi için ROM'un döviz rezervlerindeki değişim, enflasyon belirsizliği, döviz kurları, enflasyon ve faiz oranları üzerindeki etkisi analiz edilmiştir. Bu çerçevede ilk olarak, Hipotez 1 (ROM, döviz rezervlerindeki volatiliteyi azaltıcı bir etkiye sahiptir) ve Hipotez 2 (ROM, enflasyon belirsizliği üzerinde azaltıcı bir etkiye sahiptir)' in geçerli olup olmadığ1 test edilmiştir. $\mathrm{Bu}$ amaçla otoregresif koşullu değişen varyans modellerinden IGARCH modelinden yararlanılmıştır. Analiz sonucunda elde edilen bulgular, ROM'un döviz rezervlerindeki değişim volatilitesi ve enflasyon belirsizliği üzerinde anlamlı bir etkiye sahip olmadığını göstermektedir. $\mathrm{Bu}$ durum, Hipotez 1 ve Hipotez 2'nin doğrulanamadığını test etmektedir.

İkinci olarak Hipotez 3 (ROM, döviz kuru volatilitesi üzerinde azaltıcı bir etkiye sahiptir) test edilmiştir. Söz konusu test için otoregresif koşullu değişen varyans modellerinden olan EGARCH modelinden yararlanılmıştır. $\mathrm{Bu}$ amaçla ROM'un yanısıra, küresel sermaye hareketlerindeki dalgalanmaları yansıtan VIX endeksi, TCMB tarafından satılan döviz miktarı ve iki yıllık gösterge tahvil faiz oranı kontrol değişkenler olarak modele dahil edilmiştir. Analizden elde edilen bulgular, ROM'un döviz kuru volatilitesi üzerinde azaltıcı bir etkiye sahip olduğunu göstermektedir. $\mathrm{Bu}$ durum, Hipotez 3'ü doğrulamaktadır. Aynı zamanda, modeldeki asimetri etkisi, sepet döviz kur volatilitesi üzerinde negatif haberlerin pozitif haberlere göre daha güçlü bir etkisinin olduğu yönünde sinyal vermektedir.

Üçüncü olarak, IGARCH $(1,1)$ modeli tahmin sonuçlarına göre ROM, TCMB döviz rezervleri üzerinde uzun dönemde anlamlı bir etkiye sahip değildir. Buna göre "ROM, döviz rezerv pozisyonu açısından faydalıdır" hipotezi doğrulanamamaktadır.

Diğer yandan ARMA $(0,1)$ modeli sonuçlarına göre gerçekleşen enflasyonda meydana gelen artış yönündeki bir şok beklenen enflasyon üzerinde de artış yaratarak enflasyon belirsizliğine yol açmaktadır. Bununla birlikte ROM'un TÜFE enflasyon belirsizliği ve enflasyon oranı üzerinde anlamlı bir etkiye sahip olmadığı yönündeki bulgu ise ulaşılan bir diğer sonuçtur. 
Elde edilen sonuçlar bir bütün olarak değerlendirildiğinde ROM'un döviz kuru üzerinde kısmen etkisi olmakla birlikte finansal kırılganlıkların, enflasyon belirsizliğinin, enflasyon ve faiz oranları üzerindeki etkisinin ve etkinliğinin zayıf olduğu görülmektedir. Bu sonuç literatürdeki birçok çalışmanın aksine bir sonuç olmakla birlikte Keskin (2018) ve Tezer (2019)'un tespitleriyle örtüşmektedir. Dolayısıyla yeni para politikası araçları kapsamında uygulamaya konulan ROM, kendisinden beklenen etkinliği sağlamakta zayıf kalmaktadır. Buna makro ekonomik yapıdaki olumsuzluklar, yönetimsel hatalar, sermaye akımlarının içsel faktörlerden ziyade küresel ekonomik koşullar tarafından belirlenmesi gibi nedenlerin yol açtığı düşünülmektedir. Bilimsel bir yarg1 için bu nedenlerin bir başka çalışmada araştırılması literatüre katkı sağlayacaktır.

$\mathrm{Bu}$ çalışmada elde edilen sonuçlara göre ROM'un uzun dönemde de etkisini devam ettirecek şekilde dizayn edilmesi veya alternatif politika araçlarının tekrar tasarlanması gerekmektedir. Bunun için sadece iç politik ve ekonomik gelişmeleri dikkate alan politikalar yerine küresel ölçekteki tüm gelişmeleri önceleyen, ülkeler arasındaki etkisini, finansal yayılma ve buluşmayı dikkate alan dinamik politikaların izlenmesi yerinde olacaktır. Finansal stres belirleyicilerinin araştırılması, ülkeler arası finansal ve ticari bağlılığı ortaya koyan mekânsal etkilerin analiz edilmesi gerekmektedir. $\mathrm{Bu}$ sebeple politika yapıcıların, finansal istikrarın gözetilmesinde yerel makroekonomik ve parasal değişkenlerin yanı sıra uluslararası belirsizlik ve diğer ülkelerin finansal sağlığına ilişkin göstergeleri ve araştırmaları iyi izlemesi ve buna göre politika dizaynını oluşturması faydalı olacaktır.

\section{KAYNAKÇA}

Alkın, H. (2015). Yeni Uzlaşı Modelinin Eleştirisi, Post Keynesyen Enflasyon Hedeflemesi Modelleri ve Para Politikası Kuralları. (Yayımlanmamış yüksek lisans tezi). Akdeniz Üniversitesi Sosyal Bilimler Enstitüsü, Antalya.

Alper, K., Kara, H. ve Yörükoğlu, M. (2012). Rezerv Opsiyonu Mekanizması. TCMB Ekonomi Notlar1, 2012-28.

Bollerslev, T. (1986). Generilazed Autoregressive Conditional Heteroscedasticity. Journal of Econometrics, 31(3), 307-327.

Box, G. and Jenkins, G. (1970). Time Series Analysis Forecasting and Control. San Francisco: Holden-Day.

Burns, P. (2005). Multivariate GARCH with Only Univariate Estimation. Working Papers, March, http://www.burns-stat.com/pages/Working/multgarchuni.pdf

Çapar, U. (2010). Enflasyon Hedeflemesinin Enflasyon ve Output Volatilitesi Üzerindeki Etkisi. (Yayımlanmamış yüksek lisans tezi), Pamukkale Üniversitesi Sosyal Bilimler Enstitüsü, Denizli.

Çidem, Y. (2013). Enflasyon-Enflasyon Belirsizliği Merkez Bankası Bă̆ımsızlı̆̆ İlişkisi. (Yayımlanmamış yüksek lisans tezi), Tokat Gaziosmanpaşa Üniversitesi Sosyal Bilimler Enstitüsü, Tokat.

Demirhan, B. (2013). Türkiye'de Yeni Yaklaşım Çerçevesinde Para Politikalarının Finansal İstikrarı Sağlama Yönünde Uygulanması. Afyon Kocatepe Üniversitesi İktisadi ve İdari Bilimler Fakültesi Dergisi, 15(2), 567 - 589.

Engle, R. F. (1982). Autoregressive Conditional Heteroskedasticity with Estimates of the Variance of U.K. Inflation. Econometrica, 50(4), 987-1008.

Engle, R. F. and Sheppard K. (2001). Theoretical and Empirical Properties of Dynamic Conditional Correlation Multivariate GARCH. NBER Working Series. 
Sevim Nurbanu Yıldız \& Başak Karşıyakalı \& Üzeyir Aydın / Yeni Para Politikası Yaklaşımı Çerçevesinde Kullanılan Rezerv Opsiyon Mekanizması Etkinliğinin Analizi

Erdem, H. F. (2017). Gida Enflasyonunun Enflasyon Belirsizliği Üzerine Etkisi. Karadeniz Teknik Üniversitesi Sosyal Bilimler Enstitüsü Sosyal Bilimler Dergisi, 7(14), 425-436.

Ergin, A. ve Aydın, H.İ. (2017). Finansal İstikrarı Sağlamaya Yönelik Bir Araç: Rezerv Opsiyon Mekanizmas1. Batman Üniversitesi Yaşam Bilimleri Dergisi. 7(1/1), 63-75.

Greene, W. H. (2002). Econometric Analysis (Fifth Edition). New Jersey: Prentice Hall.

Hamilton, J. (1994). Time Series Analysis. New Jersey: Princeton University Press.

Kantar, L. (2017). Rezerv Opsiyon Mekanizması ve Döviz Kuru Volatilitesi: Türkiye Üzerine Bir Uygulama. (Yayımlanmamış doktora tezi). İstanbul Üniversitesi Sosyal Bilimler Enstitüsü, İstanbul.

Keskin, N. (2018). Küresel Kriz Sonrası Türkiye'de Yeni Para Politikası Yaklaşımının Benimsenmesinde Sermaye Akımlarının Rolü ve Sermaye Kontrollerine İlişkin Bir Değerlendirme. Yönetim Bilimleri Dergisi, 16(31), 161-195.

Kirchgassner, G., Wolters, J. (2007). Introduction To Modern Time Series Analysis. Berlin: Springer.

Küçüksaraç, D. ve Özel Ö.(2012). Rezerv Opsiyonu Mekanizması ve Optimal Rezerv Opsiyonu Katsayılarının Hesaplanması. TCMB Çalışma Tebliği No:12/32.

Nelson, D.B. (1991). Conditional Heteroskedasticity in Asset Returns: A New Approach. Econometrica, 59(2), 347-370.

Oduncu, A., Ermişoğlu, E. ve Akçelik, Y. (2013). Merkez Bankasının Yeni Enstrümanı Rezerv Opsiyonu Mekanizması ve Kur Oynaklı̆̆ı. Bankacılar Dergisi, 24(86), 43-52.

Özer, M. ve Türkyılmaz, S. (2004). Türkiye Finansal Piyasalarında Oynaklıkların ARCH Modelleri Ile Analizi, Yayın No:1593. Eskişehir: T.C. Anadolu Üniversitesi Yayınları.

Said, S. and Dickey, D. (1984). Testing for Unit Roots in Autoregressive-Moving Average Models of Unknow Order. Biometrika. 71(3), 599-607.

Samut, P. (2014). The Effect of Inflation Uncertainity on Price Component: The Case of Turkey. Atatürk Üniversitesi İktisadi ve İdari Bilimler Dergisi, 28(1), 21-40.

Serel, A. ve Özkurt İ. C. (2014). Geleneksel Olmayan Para Politikası Araçları ve Türkiye Cumhuriyet Merkez Bankası, Yönetim ve Ekonomi Araştırmaları Dergisi, 22. http://dx.doi.org/10.11611/JMER247

Silvennoinen, A and Terasvirta, T. (2009). Multivariate GARCH Models. Andersen, T.G., Davis, R.A., Kreib, J.P. and Mikosch, T. (Ed.), Handbook of Financial Time Series içinde (201229.ss). Berlin: Springer.

Su, C. (2010). Application of EGARCH Model to Estimate Financial Volatility of Daily Returns: The Empirical Case Of China. University of Gothenburgs School of Business Economics and Law.

Taufiq, C. (1995). Long Run Money Demand Function in Argentina During 1935-1962: Evidence from Cointegration and Error Correction Models, Applied Economics, 27(8), 661-667.

Tezer, H. (2019). Merkez Bankasının Rezerv Opsiyon Mekanizması (Rom) Uygulamaları, Para ve Döviz Kuru Karşısında Etkinliği, International Social Sciences Studies Journal, 5(29), 395-405.

Tsay, R. S. (2011). Analysis of Financial Time Series (Third Edition). New Jersey: Wiley.

Tsay, R.S. (2005). Analysis of Financial Time Series (Second Edition). New York: Wiley.

Tse, Y.K. and Tsui, A.K.C. (2002). A Multivariate GARCH Model with Time-Varying Correlations, Journal of Business and Economic Statistics, 20(3), 351-362.

Zakoian, J.M. (1994). Threshold Heteroskedasticity Models, Journal of Economic Dynamics and Control, 18(5), 931-955.

Zakoian, J.M. and Francq, C. (2010). GARCH Models: Structure, Istatistical Inference and Financial Application. West Sussex: Wiley.

\section{SUMMARY}

After the global crisis that took place process like many Central Banks of the emerging country has forced the Central Bank of Turkey to design new monetary policy tools. In this design perspective, reserve requirement ratios, 
reserve option mechanism (ROM) and asymmetric interest rate corridor have been implemented. With this implementation, the effectiveness and success of these tools have been discussed. In this context the purpose of the study, since 2010 is being implemented in Turkey investigate its impact on exchange currency reserves of the ROM, exchange rate, inflation uncertainty, inflation and interest rates and to discuss the effectiveness of the mechanism. The extent of this aim is to analyze the effect of ROM on the change in foreign exchange reserves, inflation uncertainty, exchange rates, inflation and interest rates for the periods in 2011 October - 2018 December. In the study, Autoregressive Conditional Variant Variance (GARCH) models were used to analyze involving in 2011 October 2018 December periods.

In this context firstly, Hypothesis 1 (ROM has a reducing effect on volatility in foreign exchange reserves) and Hypothesis 2 (ROM has a reducing effect on inflation uncertainty) were tested it is valid or not. For this purpose, IGARCH model which is one of the autoregressive conditional changing variance models was used. The findings of this analysis show that ROM does not have a significant effect on the volatility of exchange reserves and inflation uncertainty. This implies that Hypothesis 1 and Hypothesis 2 are not valid. Secondly, Hypothesis 3 (ROM has a reducing effect on exchange rate volatility) was tested. For this purpose, EGARCH model which is one of the autoregressive conditional changing variance models was used. For this purpose, in addition to the ROM, the VIX index reflecting the fluctuations in global capital movements, the amount of foreign exchange sold by the CBRT and the two-year benchmark bond interest rate are included in the model as control variables. The findings of the analysis show that ROM has a decreasing effect on exchange rate volatility. This implies that Hypothesis 3 is valid. At the same time, the asymmetry effect in the model signals that negative news on basket exchange rate volatility has a stronger effect than positive news.

Thirdly, according to the IGARCH $(1,1)$ model estimation results that ROM does not have a significant long-term effect on Central Bank of the Republic of Turkey foreign exchange reserves. Accordingly, the "ROM is useful for foreign exchange reserve position" Hypothesis cannot be confirmed.

On the other hand, according to the results of ARMA $(0,1)$ model, a shock in the increase in the realized inflation causes an increase in the expected inflation and leads to the uncertainty of inflation. However, reached another result the finding that ROM does not have a significant effect on inflation uncertainty and inflation rate. When the results are considered as a whole, it is seen that although ROM has some effect on exchange rate, financial fragilities, inflation uncertainty, inflation and interest rates and efficiency are weak. This result, on contrary to many studies in the literature is consistent with the results of Keskin (2018) and Tezer (2019). Therefore, the ROM implemented within the context of new monetary policy instruments remains weak in providing from the own self expected effectiveness. This is thought to be caused by the unfavorable in macroeconomic structure, administrative errors, and the determination of capital 
flows by global economic conditions rather than internal factors. However, reaching a final judgment for this is beyond the context of this study. In another study, these reasons can be investigated.

According to the results of this study, ROM should be designed to maintain in long-term impact also or require to redesign alternative policy tools. Therefore, instead of policies that only take into account domestic political and economic developments, it would be appropriate to follow dynamic policies that prioritize all developments on a global scale, taking into account the effect of financial spreading and financial contagion among countries. Investigators of financial stress determinants need to be analyzed and spatial effects of financial and commercial dependence between countries. For this reason, policy makers need to closely monitor the indicators and research related to international uncertainty and other countries' financial health as well as local macroeconomic and monetary variables in respect of the financial stability. For this reason, policy makers need to closely take out the indicators and research related to international uncertainty and other countries' financial health as well as local macroeconomic and monetary variables in respect of the financial stability. 